\title{
Solid-state Morphology Evolution of Sodium Neutralized Poly(ethylene-ran-methacrylic acid) Ionomer Under Dry and Wet Thermal Annealing
}

\author{
German H. Gómez $z^{a}$, Thiago Manha Gasparini ${ }^{a}$, Sebastião V. Canevarolo ${ }^{b *(0)}$ \\ aPrograma de Pós-Graduação em Ciência e Engenharia de Materiais - PPGCEM, Universidade \\ Federal de São Carlos, São Carlos, SP, Brasil \\ ${ }^{b}$ Departamento de Engenharia de Materiais - DEMA, Universidade Federal de São Carlos, São Carlos, \\ SP, Brasil
}

Received: August 28, 2018; Revised: December 20, 2018; Accepted: May 19, 2019

The DSC low temperature endothermic peak shown by sodium neutralized poly(ethylene-randommethacrylic acid) (E/MAA-Na+) ionomers in the range of $50-70^{\circ} \mathrm{C}$ is attributed to the endothermic reordering of polyethylene chain segments belonging to two populations of quasi-crystals set from melt, initially showing no birefringence. Dry or wet thermal annealing improve their polyethylene chain segments packing expelling out the non-crystallizable methacrylic mers by absorbing and storing heat, converting them into better-organized crystals. Upon heating further they melt, using the stored energy. Hydrothermal annealing separates the relaxation of the PE chain segments inside the ionic clusters and their reordering: i) water plasticizes the ionic clusters, downshifting the relaxation temperature, detected either by static (DSC) or dynamic (DMTA) thermal analysis and, ii) shifts upwards the endothermic peak due to the reordering of PE chain segments, detected optically by cross-polarized light and X-Ray diffraction patterns.

Keywords: E/MAA-Na+ ionomer, thermo-optical behavior, hydrothermal treatment, ionomer morphology.

\section{Introduction}

Ionomers are thermoplastics that contain a relatively low content of ionic functional groups in the polymer backbone. ${ }^{1}$ Due to the energy difference between the nonpolar carbon chains and the polar functional groups, clustering of the ionrich zones appears, leading to a nano-separation of the two regions, the ion-rich domains acting as physical crosslinks. ${ }^{2}$ Morphology's studies of semi-crystalline ionomers has been a subject of study for more than fifty years within the scientific community, due to the particular properties shown by these materials, such as high transparency, ${ }^{3}$ good mechanical behavior, ${ }^{4-6}$ capacity of self-repair ${ }^{7}$, shape memory, ${ }^{8}$ in addition to the potential use in electric cells and batteries $^{9}$, among others. Also most recently has come up studies on precision ionomers and their ability to selectively transport charged species. ${ }^{10,11}$ One of the features that have attracted most attention is the morphological transformation responsible for the endothermic peak of low temperature, visualized in calorimetric measurements.

Back in 1974 Marx and Cooper ${ }^{12}$ had already indicated that ethylene ionomers stored at ambient temperature leads to a low temperature endothermic peak in DSC scans, which they interpret as melting of folded-chain lamellae of the polyethylene chain segments. Later in 1990 Eisenberg, Hird and Moore ${ }^{13}$ proposed a morphological model for amorphous random ionomer based on the formation of

*e-mail: caneva@ufscar.br multiplets, in which the hydrocarbon polymer chain segments surrounding each multiplet experience appreciable restrictions in mobility. As the ion content increases even further these regions with restricted mobility overlaps, forming what they called "ionic clusters". Yano and Kutsumizu proposed in a series of articles ${ }^{14-22}$ starting in 1989 up to 2005 and more recently ${ }^{23}$ in 2013 that the low temperature endothermic event was an order-disorder transition of the ionic clusters in the ionomers, discarding the initial idea of melting the secondary polyethylene crystals.

Up to this moment the general consensus upon this morphological transformation was pioneered by the works of Register et al. ${ }^{4,5,24-28}$ They have used data from thermomechanical and calorimetric, ${ }^{26}$ and X-ray scattering measured under heating, ${ }^{28}$ revealing the occurrence of two simultaneous morphological transformations at this transition: i) the devitrification of the ion-rich regions and ii) the melting of the secondary crystals, similar to the proposal set forth in the Multiplet-Cluster model for random ionomer. ${ }^{13}$

Morphological models presented in the works listed above assume anhydrous conditions. The presence of ionic aggregates and their hydrophilic nature causes modifications in the ionomer morphology when water is present. ${ }^{2,29}$ Kutsumizu et al. carried out a series of studies ${ }^{15,16,20-22,30}$ using Electronic Spin Resonance Spectroscopy ESR on semi-crystalline ionomer films, observing that the size of the ionic clusters increases with the absorbed water content. From the same research group Tachino et al. ${ }^{31}$ observed that 
as the content of water increases, the endothermic peak of low temperature decreases both in temperature and enthalpy value. According to them, the incorporation of water in the clusters reduces the structural order of the ionic aggregates, with no relationship with the polyethylene crystals, a result analogous to the order-disorder model.

So far, studies of water absorption in semi-crystalline ionomers focused mainly on the modifications that occur in ionic clusters and not on the crystalline phase of the material. In this work, we employed real-time thermo-optical analysis, to better understand this low temperature thermal transition. We used a photo sensor adapted to a polarized light optical microscope q-PLOM, to be able to detect changes in the optical anisotropy, as cross-polarized transmitted light intensity (i.e. birefringence), during heating/cooling scans. Other characterization techniques, like X-Ray diffraction, DSC and DMTA, were also employed. The morphological transformations were induced in the ionomer by means of dry and wet isothermal annealing's. The thermo-optical results shows that when the semi-crystalline ionomer passes by the low temperature endothermic peak, birefringence appears and grows indicating the formation and improvement of PE crystals. We propose the use of wet-annealing to enable the separation of the structural relaxation temperature of the ionic clusters from the temperature that allows the molecular movement of the PE chain segments inside the imperfect crystals.

\section{Experimental Section}

\subsection{Materials}

The ionomer studied is the poly(ethylene-randommethacrylic acid) partially neutralized with sodium ions, E/ MAA- $\mathrm{Na}^{+}$, purchased from DuPont under the tradename of Surlyn PC2000. Such copolymer has $5.4 \mathrm{~mol} \%$ of MAA units in the backbone, $67 \%$ of this MAA comonomer is neutralized with sodium cations, average molecular weights $\mathrm{Mn}=19$ $\mathrm{kDa}, \mathrm{Mw}=95 \mathrm{kDa}$, peak melting temperature $84^{\circ} \mathrm{C}(\mathrm{DSC})$, density $0.97 \mathrm{~g} / \mathrm{cm}^{3} \cdot{ }^{32,33}$ In order to erase the thermal history of the material and eliminate the orientation crystallization, the samples used were molded in plates with two different thicknesses, $0.8 \mathrm{~mm}$ and $0.6 \mathrm{~mm}$, in hot press at $135 \pm 5^{\circ} \mathrm{C}$ for five minutes and cooled by a water circulation system. The sample was removed from the press when the mold reached $50^{\circ} \mathrm{C}$, cut and stored in a desiccator over $\mathrm{CaSO}_{4}$ during two weeks to allow the morphology to settle with no water absorption. ${ }^{26,34}$ Samples that were stored two weeks at room temperature were hydrothermally treated (HTT) immersed in distilled/deionized water for three hours at two different temperatures, $60^{\circ} \mathrm{C}$ and $70^{\circ} \mathrm{C}$. Upon treatment completion the bath was cooled down till room temperature and the samples, kept still immersed in the same water, were stored during one day, before any further measurements were done.

\section{Measurements}

Thermal analysis: Measurements were made by a DSC from TA Instruments model Q2000, calibrated with indium standard at a heating rate of $10^{\circ} \mathrm{C} / \mathrm{min}$. The heating cell was purged with dry $\mathrm{N}_{2}(50 \mathrm{ml} / \mathrm{min})$ during the measurement. Samples weights were in the range of $7-7.5 \mathrm{mg}$, cut from the hot-pressed sheet with $0.8 \mathrm{~mm}$ of thickness and enclosed in aluminum pans. The calorimeter was also used to heat treat the samples in two different ways: i) perform the required isothermal annealing on dry samples, and ii) characterize their thermal behavior by monitoring changes in the enthalpy. The DSC thermal annealing cycle consisted of a fast heating from ambient temperature up to the required annealing temperature; followed by an isothermal heat treatment during 30 minutes. The annealing temperatures chosen were 50,60 and $70^{\circ} \mathrm{C}$, set in the range between the low temperature endothermic peak and the beginning of the high temperature endothermic peak, and then cooling down to room temperature at $50^{\circ} \mathrm{C} / \mathrm{min}$. Finally, the melt behavior of the samples was measured by heating at $10^{\circ} \mathrm{C} / \mathrm{min}$ from room temperature till complete melting.

Thermo-optical analysis: a quantitative polarized light optical microscopy, q-PLOM was used to measure the cross-polarized transmitted light intensity through the sample, recorded in an optical microscope Leica model DMR $\mathrm{XP}$, set in the polarized light mode. The microscope lamp beam is first polarized by passing through the polarizer filter and reaches the sample kept in a hot-stage system CSS450 (Cambridge Shearing System) from Linkam Scientific Instruments. It was used for heating up and cooling down the ionomer samples, and to maintain constant the thickness during isothermal/nonisothermal experiments. The polarized light interferes with the optical anisotropic sample, resulting in the phenomenon of the light retardation. After emerging the light ray passes through a crossed analyzer filter which decomposes the light as cross-polarized transmitted light intensity according to a periodic sine square curve, as presented in eq 1 for green light. In order to have a simple direct correlation between cross-polarized normalized transmitted light intensity $\left(\mathrm{I}_{\mathrm{N}}\right)$ and optical path difference (OPD) it is convenient to measure samples with OPD smaller than $275 \mathrm{~nm}$, i.e., within the first half of the first order in the Michel-Levy interference color chart.

$$
I_{N}=\sin ^{2}\left(\frac{\pi^{*} O P D}{550}\right)
$$

The easiest way to get optical path difference below $275 \mathrm{~nm}$ is to prepare samples thin $(\mathrm{t})$ enough, which will show interference color in the range black-silver, when visually observed in the PLOM. Due to the low intrinsic birefringence $(\Delta n=\mathrm{OPD} / \mathrm{t})$ values of the E/MAA-Na+ ionomer, samples with $0.8 \mathrm{~mm}$ of thickness were found to be suitable for these measurements. Films with this range 
of thickness are easily obtained from hot-pressed molding, as used here. Even though a systematic visual checking of the interference color under cross-polarized illumination at room temperature was done in every sample while thermooptical measurements were to be performed, choosing the ones showing silver color.

The cross-polarized transmitted light intensity was measured by a home-made detection system. It consists of a plate holding a photocell of the type light dependent resistor (LDR), covered with an analyzer filter. The plate is inserted in the slot of the microscope, used to hold the analyzer filter. The light beam coming from the sample passes through the analyzer filter and then reaches the photocell. The photocell is electrically connected to a signal handling box, which converts the incident light intensity into an electric voltage. This analogic signal is converted to digital via an $\mathrm{AD} / \mathrm{DA}$ interface (USB data acquisition device NI-DAQ 6225) that further feeds a personal computer. To handle the signal, a software was developed in LabView 8.6 platform (National Instruments) for data collection, real-time calculation, data screen presentation and storage. The incoming signal from the photocell is normalized by setting the minimum and maximum light intensity limits defined by measurements done without sample at crossed-polars and parallel-polars respectively. Thus, the normalized voltage range is between 0 and 1 . The data collection system continuously monitors the thermal measurements. For a direct comparison the DSC and q-PLOM analysis were done using the same heating/ cooling cycles.

The thermo-optical measurements were done in samples with thickness carefully controlled; it directly affects the optical path difference OPD, as presented in eq1. The thickness of the samples was measured by a Mitutoyo MDC-25SX micrometer and any specimen not being within a $0.80 \pm 0.05 \mathrm{~mm}$ pre-set limit was discarded. The samples were placed in the CSS 450 hot stage system, the gap between the two quartz windows adjusted until full contact with the sample's up and lower surfaces was obtained.

X-Ray Diffraction pattern: The AXS diffractometer from Analytical X-Ray Systems Siemens D5005, operating with a power of $1600 \mathrm{~W}=40 \mathrm{kVx} 40 \mathrm{~mA}, \mathrm{Cu}-\mathrm{K}$ alpha radiation, wavelength $\lambda=1.54056 \AA$, was used. The $2 \theta$ diffraction angle was swept between 1.5 to $30^{\circ}$ at $2^{\circ} / \mathrm{min}$, with step size of $0.02^{\circ}$. Measurements were made at room temperature. Samples were previously thermal annealed in the Linkam hot stage CSS450 system. To avoid the sample sticking to the quartz windows of the hot stage causing its distortion while their removal, they were sandwiched between two Kapton ${ }^{\circledR}$ sheets. Samples hydrothermally treated were prepared following the procedure presented earlier. Samples were cut from the $0.8 \mathrm{~mm}$ original thick plate.

Dynamic-Mechanical Thermal Analysis. The measurements were conducted on a DMTA from TA Instruments Q800, using the film tension mode. The experiments were made at an oscillation frequency of $10 \mathrm{~Hz}$, elongation amplitude of $0.1 \%$ (in order to be within the linear region of viscoelasticity), and temperature range from 25 to $85^{\circ} \mathrm{C}$, at a heating rate of $3{ }^{\circ} \mathrm{C} / \mathrm{min}$. Dry-annealed and hydrothermally treated HTT samples had the same preparation procedure described previously. The specimens were cut in rectangular geometry with dimensions of $13.5 \mathrm{~mm} \times 6.5 \mathrm{~mm}$ from hot-pressed sheets with $0.6 \mathrm{~mm}$ thickness.

\section{Results and Discussion}

\subsection{Thermal and thermo-optical behavior of E/ $M A A-\mathrm{Na}^{+}$ionomer after dry annealing at room temperature}

As a starting point the thermal behavior of the sample cooled from the melt and dry-stored for two weeks at room temperature was measured in a DSC. The heating curve, presented in Figure 1, shows the expected behavior of a semi-crystalline ionomers, consisting of two endothermic peaks. The first one, seen at low temperature, has still a quite controversial interpretation, the literature presenting several hypotheses for its morphological transformations $\mathbf{s}^{14,28,26,35}$, being the main subject of this paper. The second one is a broad peak set at high temperature, in the range of $80^{\circ} \mathrm{C}$, which has been attributed in the literature as the melting temperature range of the PE primary crystals, crystallized during the previous cooling down from the molten state. It

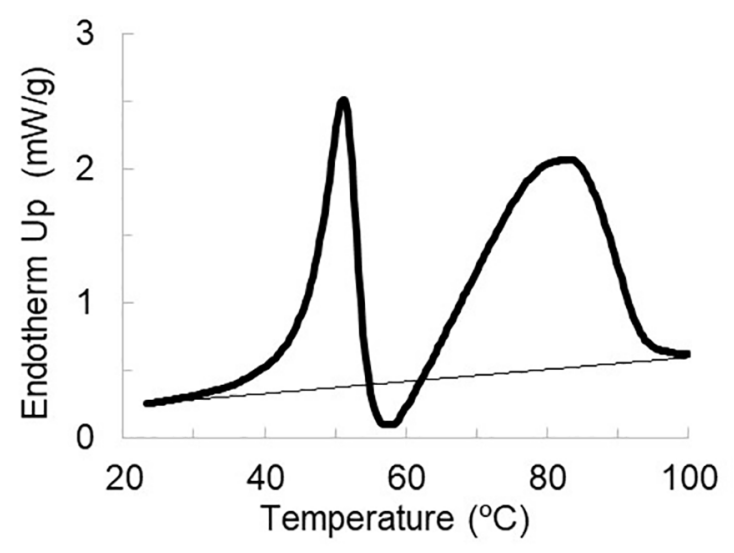

Figure 1. DSC heating curve of E/MAA-Na ${ }^{+}$ionomer after dryannealing at room temperature during two weeks. The straight line shown is one possible baseline.

is said to be broad due to the wide distribution of crystal sizes and lamella thicknesses. ${ }^{12,36,37}$

The initial crystalline fraction, calculated from the summation of the enthalpies of the low and high temperature endothermic peaks (using the PE's single crystal heat of fusion $\left.\Delta \mathrm{H}^{\circ}=278 \mathrm{~J} / \mathrm{g}^{38}\right)$ is $(46 / 278)^{*} 100 \%=17 \%$, in agreement with data reported in the literature. ${ }^{26}$ 
The thermo-optical behavior of the semi-crystalline ionomer was also evaluated using the q-PLOM analysis. To ensure that the birefringence observed in the q-PLOM corresponded only to intrinsic birefringence (excluding other types like orientation-birefringence or deformationbirefringence) all samples were first tested for that as: The sample films were positioned at the hot-stage and while rotated a $360^{\circ}$ the cross-polarized transmitted light intensity was synchronously measured. After one complete turn a constant cross-polarized transmitted light intensity value indicates that the sample presents no preferential orientation nor frozen deformation, the effect is due only to the intrinsic birefringence coming from the PE crystals. Only samples passing this criterion were used.

Figure 2 shows the thermo-optical behavior of the semicrystalline ionomer during the first heating. Starting from room temperature the cross-polarized transmitted light intensity initially is very low, almost equal to the minimum established during the normalization of the signal. This indicates that the sample's optical anisotropy generated by the ionomer morphology is very low, almost out of the detection of the q-PLOM.

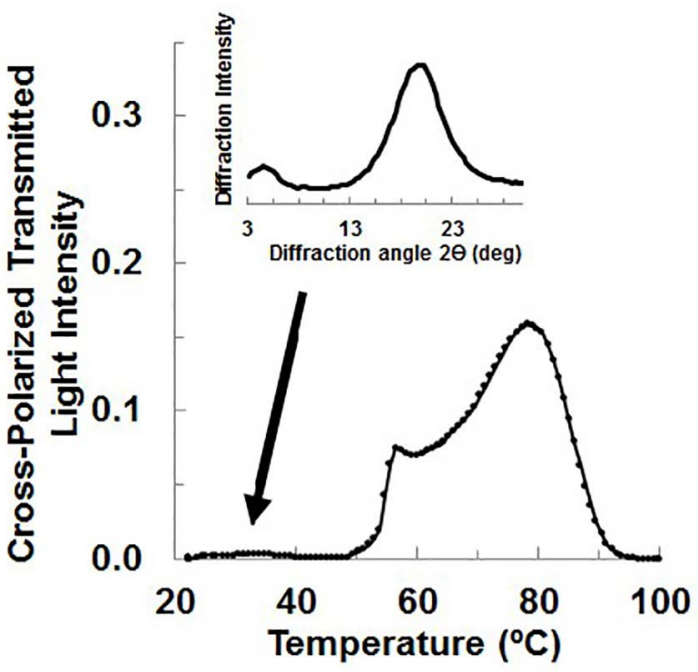

Figure 2. q-PLOM heating curve of E/MAA-Na+ ionomer after dry annealing at room temperature during two weeks. In the inset, its X-Ray diffraction pattern measured at room temperature, before the q-PLOM heating scan.

The very low initial cross-polarized transmitted light intensity, shown by the q-PLOM measurement indicating a negligible OPD or birefringence was not expected taking into account the presence of the endothermic peak shown by the DSC trace (Figure 1). To better understand this result a qualitative X-Ray Diffraction (XRD) analysis, seen as an inset in Figure 2, was performed in order to evaluate the level of short-range order in the sample. XRD pattern shows a broad and weak peak, centered at $19^{\circ}$, which can be interpreted as the diffraction halo of the amorphous PE phase. ${ }^{19,23}$ Characteristic diffraction peaks of the standard orthorhombic PE crystals are not present. The optical (q-PLOM) and spectroscopic (XRD) responses indicates that there are no segregated entities, like the attributed in the literature, as PE crystals. Any entity, if present, not interfering with the cross-polarized transmitted light nor the X-ray diffraction, ought to be devoid of any short range order. According to Keating and McCord, when a copolymer is fast cooled from the melt it forms structures with low morphological order. ${ }^{39}$ We can also take into account the uniform inclusion model proposed by Sanchez and Eby ${ }^{40}$ which states that the noncrystallizable comonomer mers could be set as part of the lamella, creating imperfect crystals, that we will call here "quasi-crystals". These regions do not have yet sufficient spatial order in the PE chain segments to produce X-ray diffraction nor birefringence patterns. In addition, one should not exclude the possibility of them having some level of chain folding, resulting from the random coil conformation of the ionomer chains, present in the molten state.

Upon heating the low optical anisotropy, as crosspolarized transmitted light intensity, remains very low till approaching $50^{\circ} \mathrm{C}$, when an abrupt increase is detected, as shown in Figure 2. This type of optical signal is the same as that visualized during a solid-state recrystallization. ${ }^{41,42}$ At this same temperature range the DSC curve shows the so-called low temperature endothermic peak. We directly relate both optical and calorimetric responses. During the cooling down from the melt to room temperature amorphous polyethylene chain segments pack together forming what we call "quasi-crystals", structures still devoided of any short range order, dispersed in the ionomer. Upon heating up to the maximum of the low temperature endothermic peak a solid morphological transformation occurs, which increases the structural order of the PE chain segments in the quasi-crystals structures. The endothermic behavior shown by the DSC is the reordering inside these PE quasi-crystals, which needs to overcome the energetic barrier imposed by the intense restriction in the mobility of the $\mathrm{PE}$ chain segments present in the ionic clusters, thus being an endothermic phenomenon. Loo et.al, in their studies of variable-temperature X-ray scattering, interpret this peak as the melting of secondary crystals since it is followed by an increase in the Bragg spacing. ${ }^{28}$ However, the refining processes and/or thickening of imperfect crystals can change the scattered light intensity and/or the scattering angle. ${ }^{43}$ Taking into account the wide XRD spectrum in semi-crystalline ionomers, the increasing in Bragg spacing could also be interpreted as a thinning of the original imperfect quasi-crystals, towards a betterorganized structure.

Upon increasing the temperature further the E/MAA$\mathrm{Na}+$ ionomer shows a new morphological reordering starting from $60^{\circ} \mathrm{C}$ up to $77^{\circ} \mathrm{C}$, with increasing the cross-polarized transmitted light intensity shown by the q-PLOM. In this same temperature range the DSC traces have shown an 
endothermic peak that has been interpreted as melting of the primary crystals. The optical measurement directly supports that the endothermic phenomenon detected by the DSC analysis (up to $77^{\circ} \mathrm{C}$ ) cannot be due to a melting process. The cross-polarized transmitted light intensity data measured here reaches less than $20 \%$ of the full scale, well inside the first half of the first order in the cross-polarized light interference chart, guaranteeing its direct correlation to the birefringence. To better understand this endothermic phenomenon dry-thermal annealing were performed in the $\mathrm{E} /$ MAA-Na+ ionomer, which will be discussed next. Finalizing the presentation of the data curve shown in Figure 2, the cross-polarized transmitted light intensity above $77^{\circ} \mathrm{C}$ drops down to zero, indicating a complete loss of short range order, caused by the melting of any well-organized structure, i. e. the PE crystals.

\subsection{Morphological changes in the E/MAA-Na+ ionomer during and after dry annealing}

Several studies are reported in the literature describing the morphological changes in semi crystalline ionomers after subjected to thermal treatments. ${ }^{12,26,44}$ In this work, we systematically monitored in real time the thermo-optical behavior of E/MAA- $\mathrm{Na}^{+}$ionomer during the isothermal annealing and its effect afterwards. In addition a detailed study of this same isothermal heat treatment was done in the DSC. Three isothermal heat treatment temperatures were chosen, within the first and second endothermic peaks range, shown by the DSC trace, more specifically at $50^{\circ} \mathrm{C}$, $60^{\circ} \mathrm{C}$ and $70^{\circ} \mathrm{C}$.

The effect of these thermal annealings obtained by the q-PLOM thermo-optical measurement is shown in Figure 3.Figure 3 a shows that the $\mathrm{E} / \mathrm{MAA}-\mathrm{Na}^{+}$ionomer presents at room temperature a very low cross-polarized transmitted light intensity, as already seen and discussed in Figure 2. Starting the heat cycle the sample is heated up to $50^{\circ} \mathrm{C}$ when the scan stops and the isothermal heat treatment of 30 minutes starts. At this annealing temperature the cross-polarized transmitted light intensity increases, shown as vertical lines, but only slightly, indicating that morphological rearrangements of crystallizable PE segments is happening, but to a very low extent. When cooling down to room temperature the crosspolarized transmitted light intensity remains almost constant, keeping the morphology as set at the $50^{\circ} \mathrm{C}$ annealing step.

When higher isothermal annealing temperature, i.e. at $60^{\circ} \mathrm{C}$ is applied, the increase in the cross-polarized transmitted light intensity during the heat treatment is significantly higher, which remains almost constant during the next step of cooling down to room temperature. The annealing at even higher temperature, i.e. at $70^{\circ} \mathrm{C}$ leads to a lower increase in cross-polarized transmitted light intensity than that recorded during the heat treatment at $60^{\circ} \mathrm{C}$, because at these higher temperatures the short PE segments, which would crystallize at lower temperature, do not have any more the favorable thermodynamics condition to crystalize. Upon the following cooling these same PE chain segments reorder and crystallizes, increasing further the cross-polarized transmitted light intensity. The cooling down data curve of $70^{\circ} \mathrm{C}$ heat treated samples follow just above the data curve of samples heat treated at $60^{\circ} \mathrm{C}$. Samples annealed at these high temperatures $\left(60^{\circ} \mathrm{C}\right.$ and $\left.70^{\circ} \mathrm{C}\right)$ keep the high morphological order when cooled down to room temperature.

Upon starting the second and final heating scan, shown in Fig. 3b, a steady increase in the cross-polarized transmitted light intensity is observed for the sample annealed at $50^{\circ} \mathrm{C}$, starting from approximately $60^{\circ} \mathrm{C}$, peaking at $77^{\circ} \mathrm{C}$ and then

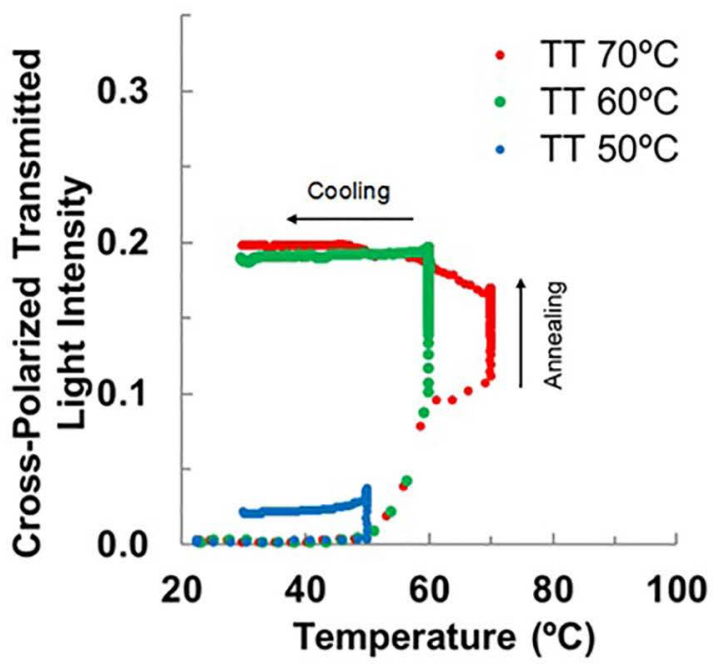

a)

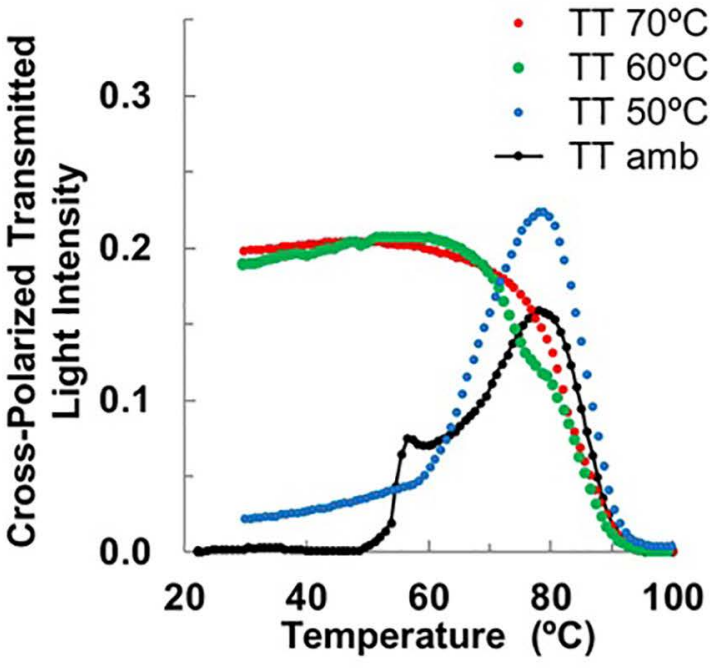

b)

Figure 3. a) Cross-polarized transmitted light intensity (q-PLOM) curves of E/MAA-Na+ ionomer during the first heating followed by dry-annealing at $50^{\circ} \mathrm{C}, 60^{\circ} \mathrm{C}$ and $70^{\circ} \mathrm{C}$ during 30 minutes, and b) the final full heat scan after each annealing. The starting samples show no birefringence, which is gained upon heating and dry annealing. 
dropping to zero. This same optical behavior is present by the sample annealed at room temperature (continuous line). Samples annealed at $60^{\circ} \mathrm{C}$ and $70^{\circ} \mathrm{C}$ show high values of the cross-polarized transmitted light intensity at room temperature, indicating the presence of PE crystals formed during the thermal annealing, which melt all together upon heating above $77^{\circ} \mathrm{C}$. A close look to these two last heating curves does show some differences between them. The sample annealed at $60^{\circ} \mathrm{C}$ shows two temperature regions where the cross-polarized transmitted light intensity drops significantly, at $70^{\circ} \mathrm{C}$ and at $77^{\circ} \mathrm{C}$. This is an experimental evidence of the presence of two different crystal populations under structural transformation in this short range of temperature. Meanwhile, the sample annealed at $70^{\circ} \mathrm{C}$ shows a single gradual drop after $76^{\circ} \mathrm{C}$, a thermal gap of just $6^{\circ} \mathrm{C}$. All samples drops to zero at approximately $92^{\circ} \mathrm{C}$, showing the melting of all PE crystals.

To explain the changes in the short-range order presented in Figure 3, the samples were isothermally annealed in the DSC (isothermal curves not shown). Figure 4 shows the DSC heating scan of these annealed samples. The curves after each heat treatment are similar to those reported in the literature, in which the low temperature endothermic peak shifts to higher temperatures with the increasing of the annealing temperature. This shift has been interpreted as the thickening of the lamellae of the secondary crystals. ${ }^{12,26,44}$

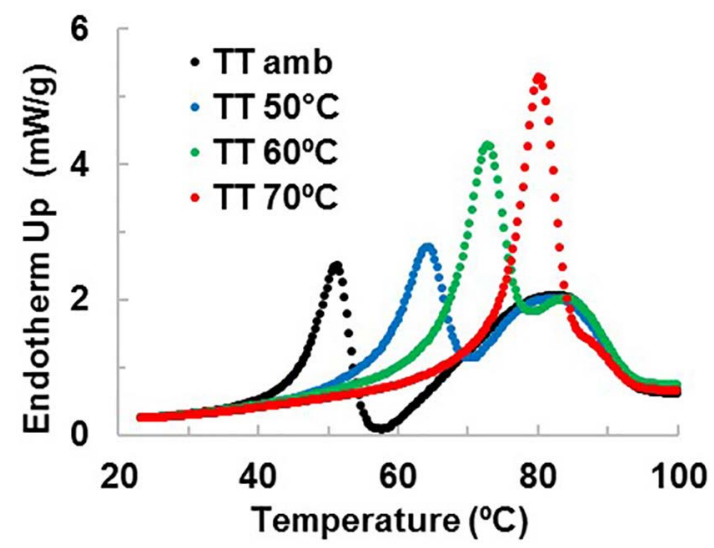

Figure 4. DSC heating curves of E/MAA-Na+ ionomer after dry annealing during two weeks at room temperature and heat treated at $50^{\circ} \mathrm{C}, 60^{\circ} \mathrm{C}$ and $70^{\circ} \mathrm{C}$ during $30 \mathrm{~min}$. The low temperature endothermic peak shifts upwards till superimpose to the melting peak of the PE crystals at $\sim 80^{\circ} \mathrm{C}$.

To understand the thermal behavior of the E/MAA- $\mathrm{Na}^{+}$ semicrystalline ionomer during heating and quantitatively evaluate the calorimetric modifications in the endothermic peaks the DSC curves were mathematically deconvoluted into various contributing symmetrical curves. Various types and number of curves were tested and the set that better fitted the experimental DSC trace was one Lorentz (Eq. 2) and three Gaussian (Eq. 3) curves, numbering four in all.

$$
\text { Heat flow }(\text { Lorentz })=\frac{2 \Delta H^{*} \mathrm{w}}{4 \pi(T-T p)^{2}+\mathrm{w}^{2}}
$$

$$
\text { Heat flow }(\text { Gauss })=\frac{\Delta H}{\mathrm{w} \sqrt{(\pi / 2)}} e^{-2}(T-T p)^{2} / \mathrm{w}^{2}
$$

being $\Delta \mathrm{H}$ (enthalpy) the area under the curve, w the curve width and $\mathrm{Tp}$ the temperature at the maximum (peak) of the simulated curve. Figure 5 shows each one of the four deconvoluted curves, the resultant summing up curve and the experimentally measured DSC curve. The four curves are numbered sequentially from the lower to the higher temperature peaks values as P1 (Lorenz) and P2, P3, P4 (Gaussian).

The setting of a baseline curve (type, starting and finishing points) is always a trick job and this is particularly true for semi-crystalline ionomers. Rui and $\mathrm{Grady}^{34}$ pointed out to this fact highlighting that ionomers exhibit a change in heat capacity of the crystalline phase during melting, which renders difficult its definition. Their heat capacity is lower at temperatures just below the melting point than above it, due to the influence of the ionic clusters, still present in the ionomer's molten state. Since it is a method subject to errors, the results of the deconvolution should be taken with care and be supported by other characterization techniques, if possible. Each individual curve was simulated by fitting three parameters: peak melting temperature (maximum point), peak width, and partial peak enthalpy (area under the curve). A forth parameter, the summation of these partial enthalpies were calculated and presented. The main parameters of all deconvoluted curves are summarized in Figure 6, plotted as a function of the annealing temperature of the E/MAA-Na ${ }^{+}$ionomer.

Starting from Figure $6 \mathrm{a}$, analyzing the peak temperature Tp's, one can see that they are all dependent upon the annealing temperature, shifting linearly towards higher Tp's values as the ionomer is subjected to higher annealing temperatures. The effect is much more pronounced for the two lower endothermic peaks (P1 and P2), shifting Tp1 and Tp2 almost $12^{\circ} \mathrm{C}$ higher than the annealing temperature. For the other two endothermic peaks (P3 and P4), Tp3 and Tp4 also increase but at a much slower rate. Each one of these Tp's are directly related with the temperatures in which changes in the optical behavior is present, as shown in Figure $3 \mathrm{~b}$. Samples annealed at room temperature or at $50^{\circ} \mathrm{C}$ while passing by the temperature range between $\mathrm{Tp} 1\left(47.5^{\circ} \mathrm{C}\right.$ for TTamb and $60^{\circ} \mathrm{C}$ for $\left.\mathrm{TT} 50^{\circ} \mathrm{C}\right)$ and $\mathrm{Tp} 2\left(51^{\circ} \mathrm{C}\right.$ for TTamb and $64.4^{\circ} \mathrm{C}$ for $\mathrm{TT} 50^{\circ} \mathrm{C}$ ) the cross-polarized transmitted light increases, revealing the already mentioned solid-state reordering of the quasi-crystals during heating. On the other hand, samples annealed at higher temperatures when passing by $\mathrm{Tp} 1$ $\left(69^{\circ} \mathrm{C}\right.$ for $\mathrm{TT} 60^{\circ} \mathrm{C}$ and $76^{\circ} \mathrm{C}$ for $\left.\mathrm{TT} 70^{\circ} \mathrm{C}\right)$ and $\mathrm{Tp} 2\left(73^{\circ} \mathrm{C}\right.$ for TT $60^{\circ} \mathrm{C}$ and $80.5^{\circ} \mathrm{C}$ for $\mathrm{TT} 70^{\circ} \mathrm{C}$ ) exhibit a significant drop in the cross-polarized transmitted light intensity revealing a reduction in the PE crystals' content. DSC measurements always present these different morphological changes as endothermic peaks (Figure 4). 

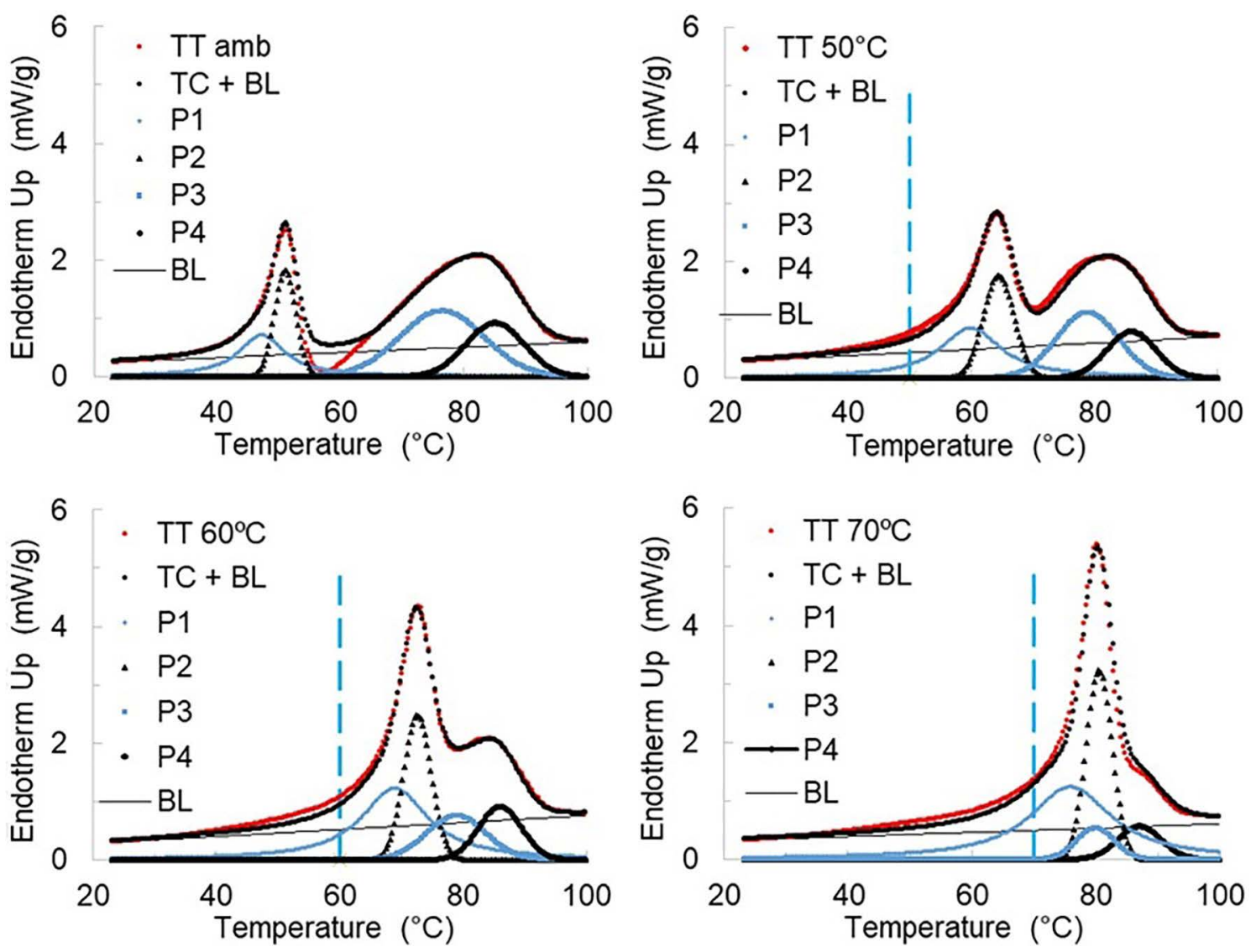

Figure 5. DSC thermal behavior during heating of E/MAA-Na+ ionomer previously annealed at $50^{\circ} \mathrm{C}, 60^{\circ} \mathrm{C}$ and $70^{\circ} \mathrm{C}(30 \mathrm{~min})$ and their deconvoluted four symmetrical curves. Vertical broken lines indicate the heat treatment temperature.

Another fact is that as the annealing temperature increases, the value of $\mathrm{Tp} 1$ linearly extrapolates to $\mathrm{Tp} 3$ and $\mathrm{Tp} 2$ extrapolates to $\mathrm{Tp} 4$. This indicates that each pair of curves (P1::P3 and $\mathrm{P} 2:: \mathrm{P} 4)$ are related to each other, i.e. we may consider these two pairs of curves, endothermic transformations occurring in two different populations, having each one of them its particular type of PE crystal. Taking into account the extrapolated melting temperatures for each pair of populations, $81^{\circ} \mathrm{C}$ and $87^{\circ} \mathrm{C}$, we may calculate the maximum $\mathrm{PE}$ average crystal size using the equation proposed by Höhne ${ }^{45}$, obtaining $5.6 \mathrm{~nm}$ and $6.2 \mathrm{~nm}$ respectively. These two values correspond to PE chain segments with an average number of methylene carbon atoms between two consecutive MAA mers of 44 and 52 carbons (rounded to even numbers). The PE crystal thickening happens while their thickness are still thinner than the maximum PE average crystal size, with the consequent increase of the ionomer intrinsic birefringence. Conversely, $\mathrm{Tp} 3$ and $\mathrm{Tp} 4$ do not increase significantly because the reordering converts the quasi-crystal into crystals with thickness near to and limited by the maximum average number of ethylene mers between two MAA mers (as already estimated).
Figure $6 \mathrm{~b}$ shows the partial enthalpy, of each four deconvoluted curves. The enthalpy of the two low temperature endothermic peaks, $\Delta \mathrm{H} 1$ and $\Delta \mathrm{H} 2$, increases consistently with the increase in the annealing temperature. This is caused by reordering and better packing the PE chain segments by expelling out non-crystallizable MAA mers off the crystals and thickening them. For that energy is needed, the newly reordered crystal absorbs and stores it. Concomitantly $\Delta \mathrm{H} 3$ and $\Delta \mathrm{H} 4$, associated with the melting endothermic peak, gradually decreased as a function of the annealing temperature. The thermal annealing creates crystals highly energetic, enough to melt them when their melting temperature is reached.

Figure $6 \mathrm{c}$ shows the summation of the partial enthalpies into two sets of curves: i) the total enthalpy and, ii) the added enthalpy of the same transformation, either crystal reordering or crystal melting.

The total enthalpy $\Delta \mathrm{H}_{\mathrm{t}}$ shown by the E/MAA-Na ionomer annealed at temperatures up to $50^{\circ} \mathrm{C}$ is low. These low temperatures do not provide sufficient mobility for the PE chain segments located in the amorphous regions to reorder, but some reordering starts to take place in the PE chain segments of the quasi-crystals, resulting in better organized and thicker crystals. The shifting of $\mathrm{Tp} 1$ and $\mathrm{Tp} 2$ 


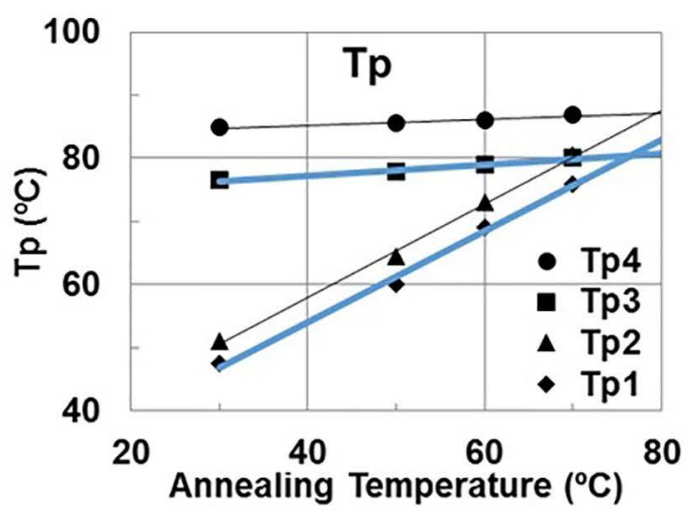

a)

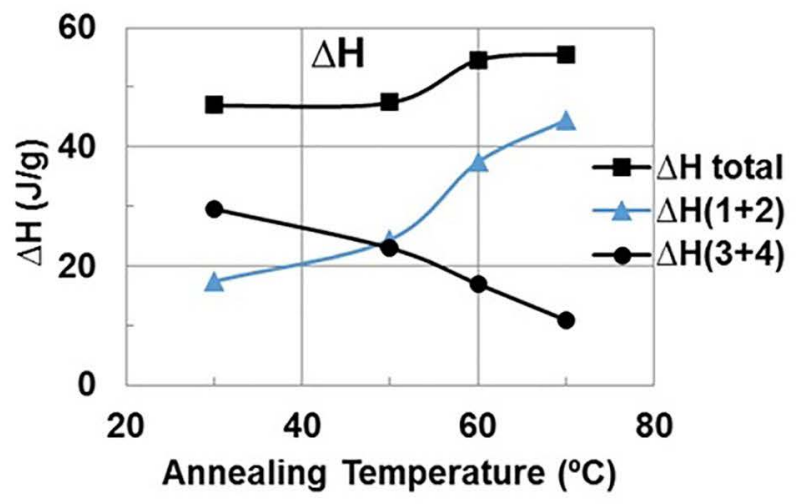

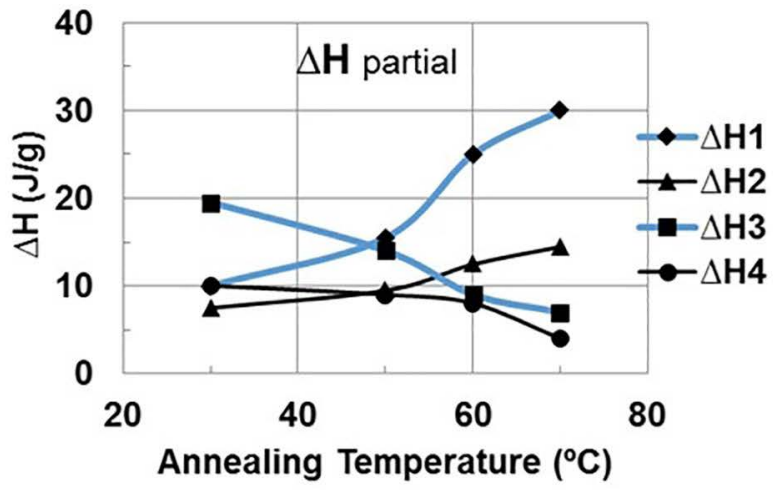

b)

c)

Figure 6. Effect of the annealing temperature on the parameters of the P1, P2, P3 and P4 simulated deconvoluted curves: a) Tp, peak melting temperature, b) $\Delta \mathrm{H}$, partial enthalpy of each individually deconvoluted curve, c) $\Delta \mathrm{Ht}$, total enthalpy (summation of the enthalpy of all four endothermic peaks) and enthalpy of each crystal transformation, $\Delta \mathrm{H}(1+2)$ relative to the crystals reordering and $\Delta \mathrm{H}(3+4)$ crystals melting peak enthalpies.

to higher temperatures (Figure 6.a) and the small increase in the cross-polarized transmitted light intensity (Figure 3a) corroborate this assumption. The thermal annealing done at $60^{\circ} \mathrm{C}$ shows an increase in the total enthalpy $\Delta \mathrm{Ht}$, which means an increase in the overall endothermic effect, including the endothermic contribution of the PE chain segments reordering into the ever-thickening crystals and their final melting. At these high annealing temperatures the thermo-optical behavior shows a substantial increase in the cross-polarized transmitted light intensity, corroborating that chain reordering is taken place inside of already existing PE imperfect crystals converting them into a better-organized PE crystals. Annealing at $70^{\circ} \mathrm{C}$ shows that the reordering conversion gets lower as the annealing temperature gets closer to the melting temperature.

The second set of curves in Figure $6 \mathrm{c}$ deals with the summed enthalpy due to the same transformation, either crystal reordering (P1 and P2) or crystal melting (P3 and P4). The curves follow opposite paths, the enthalpy for the crystal reordering, $\Delta H(1+2)$, increases continuously indicating the ever-thickening of the crystals and their increasing energy storage. On the other hand the extra external energy needed to melt the crystals, $\Delta \mathrm{H}(3+4)$, drops down, a great part of the energy needed to melt them is already stored from the previous endothermic reordering phenomenon. We reckon that this curve extrapolates to zero and the first one to the total enthalpy $\Delta \mathrm{H}_{\mathrm{t}}$ when the annealing temperatures reaches the melting temperature.

\subsection{X-Ray diffraction of E/MAA-Na+ionomer after dry-annealing}

The effect of the dry-annealing in the ionomer crystalline $\mathrm{PE}$ chain packing was analyzed by X-Ray diffraction measured at room temperature, the results presented in Figure 7. The diffraction pattern of the ionomer without annealing (already seen as an insert in Figure 2), presents a broad halo centered at $19^{\circ}$, typical of an amorphous polymer. When the ionomer is annealed at $50^{\circ}, 60^{\circ}$ and $70^{\circ} \mathrm{C}$, two weak diffractions peaks appear; a clear peak at $21^{\circ}$ and a shoulder at $23^{\circ}$, corresponding respectively to the diffraction planes (110) and 
(200), due to the PE orthorhombic crystals. Their intensity increases as the annealing temperature increases indicating a weak reorganization of the amorphous $\mathrm{PE}$ chain segments of the quasi-crystals increasing slightly the crystallinity of the heat treated ionomer. The small intensity and broad width of the diffraction peaks indicates PE crystals which are small, imperfect and may contain MAA mers ${ }^{43,46}$. All $\mathrm{X}$-Ray diffraction patterns present a peak at diffraction angle of $3.9^{\circ}$ the so-called "ionomer peak".$^{19,23,29}$ The results so far indicate that the reordering of the PE chain segments and their morphological changes are mainly thermally induced.

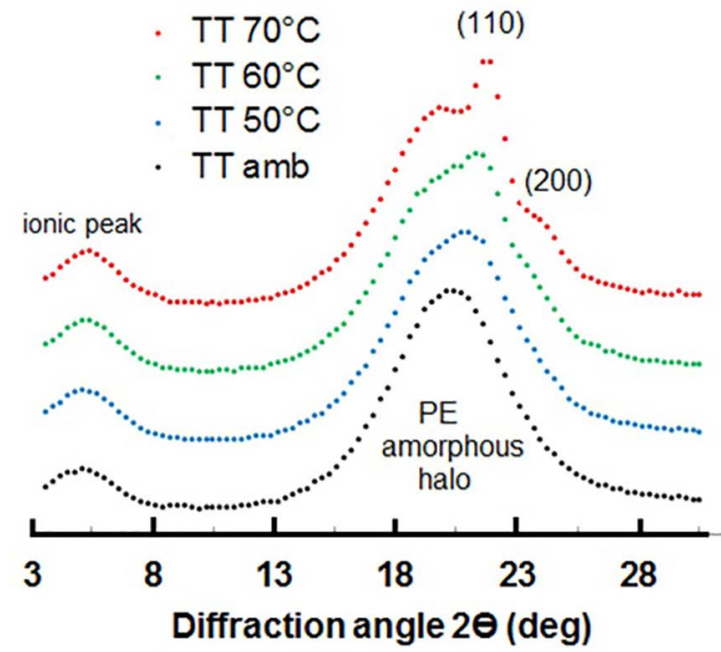

Figure 7. X-Ray diffraction pattern of E/MAA-Na+ ionomer after dry annealing at $50^{\circ} \mathrm{C}, 60^{\circ} \mathrm{C}$ and $70^{\circ} \mathrm{C}$, compared to the amorphous halo of the dry annealed ionomer at room temperature.

\subsection{Dynamic-mechanical thermal analysis of E/ $M A A-N a+$ ionomer after dry-annealing}

Several works in the literature deals with the dynamicmechanical thermal behavior of semi-crystalline ionomers, showing the presence of various relaxation temperatures during heating., ${ }^{4,17,26,47}$ Here we will focus particularly in the thermal transitions that occur in the range of room temperature up to the melting of the PE crystals of E/MAA- $\mathrm{Na}^{+}$ionomer.

Figure 8 shows the effect of dry-annealing the E/MAA- $\mathrm{Na}^{+}$ ionomer in the elastic (E') and loss (E') moduli and damping ( $\tan \delta)$ dynamic-mechanical parameters. Ionomer that was only dry-annealed at room temperature shows changes in all DMTA variables in the temperature range of $50^{\circ} \mathrm{C}$ to $55^{\circ} \mathrm{C}$ : a drop in the storage modulus ( $\left.\mathrm{E}^{\prime}\right)$, a peak in the loss modulus ( $\left.\mathrm{E}^{\prime \prime}\right)$ and an strong increase in the damping Tan $\delta$, indicating the dependence of the relaxation of $\mathrm{PE}$ chain segments with the ionic interactions, strongly present in these temperatures. ${ }^{29}$ This transition has been interpreted by Wakabayashi and Register as relaxation C, when the secondary crystals melt and creates breaks in the rigid-path way, accelerating the drop in the elastic modulus $\mathrm{E}^{\prime}{ }^{26}$ At temperatures below the relaxation $\mathrm{C}\left(40 \sim 50^{\circ} \mathrm{C}\right)$, the $\mathrm{PE}$ chain segments in the amorphous region cannot reorganize themselves, maintaining the random conformation. At this temperature range the crystallization elastic-entropic forces are lower than the electrostatic forces of the ion clusters, explaining the morphological behavior of $\mathrm{E} /$ MAA-Na ${ }^{+}$ionomer when crossing the low endothermic peak. When this relaxation temperature is exceeded, part of the PE chain segments inside the quasi-crystals can reorganize and so crystallize. But, due to the hindrance in the ionic clusters, the crystallization is only possible for the $\mathrm{PE}$ chain segments which are far from the ionic core. ${ }^{29}$

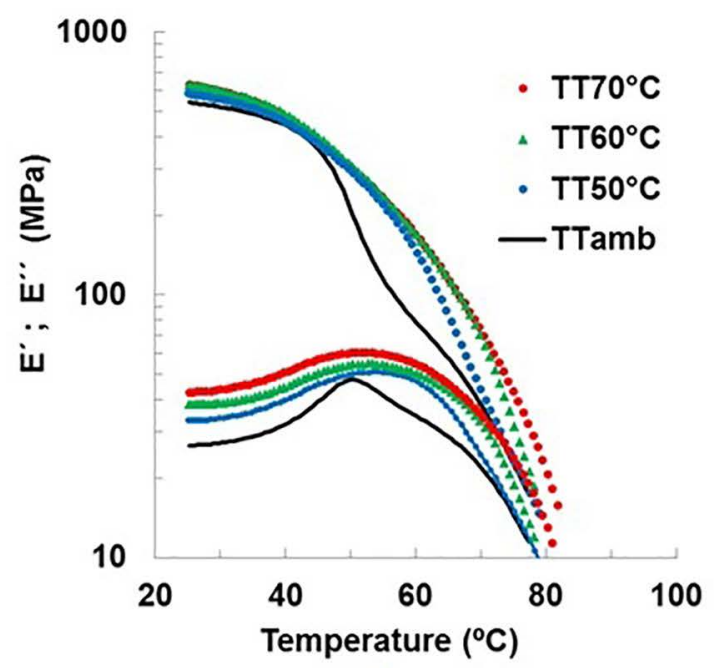

a)

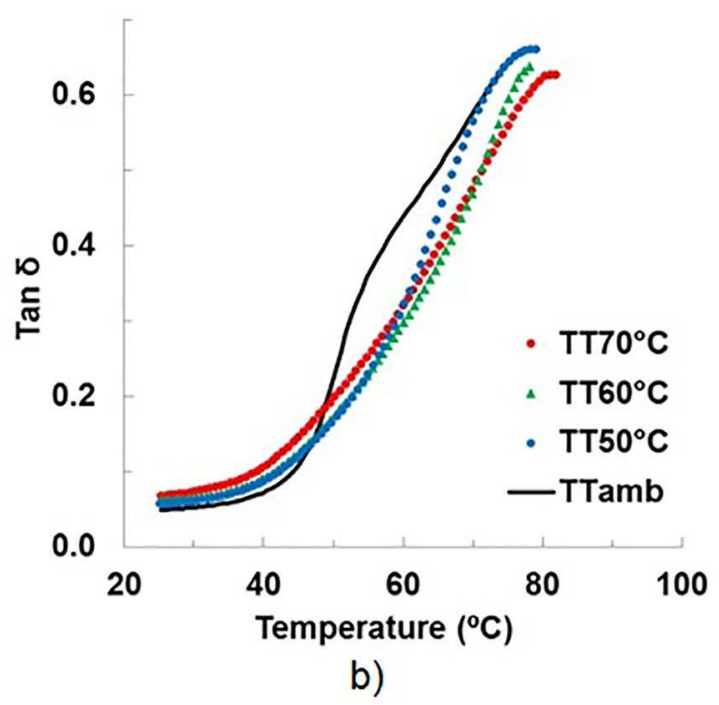

Figure 8. Dynamic-mechanical thermal analysis data of $\mathrm{E} / \mathrm{MAA}-\mathrm{Na}+$ ionomer after thermal annealing at room temperature, $50^{\circ} \mathrm{C}, 60^{\circ} \mathrm{C}$ and $70^{\circ} \mathrm{C}$. a) Storage $\left(\mathrm{E}^{\prime}\right)$ and Loss $\left(\mathrm{E}^{\prime \prime}\right)$ moduli and b) Damping (Tan $\left.\delta\right)$. 
With the dry-annealing, the relaxation of semicrystalline ionomer shifts to higher temperatures due to the synergistic effect between crystals and the ionic clusters, ${ }^{26}$ being able to modify the structural transformation during heating. To understand the contributing effects in this transition, we propose here an experimental method by which the relaxation of the ionic clusters and the molecular reordering of the PE chain segments in the crystals could be separated and so measured independently. One of the ways would be increasing at the same time the size of both, ionic cluster and PE crystals. This proposed method, called hydrothermal treatment (HTT), subjects the E/MAA-Na ${ }^{+}$ionomer to a thermal wet-annealing in direct contact with water. The PE chain segments are highly hydrophobic, then presenting an insignificant water swelling; in contrast, water molecules will be taken up by the ionic aggregates, which are polar and highly hygroscopic. The interaction of water molecules with the ion cluster and the effect of annealing the PE crystals modify the morphology of the semi-crystalline ionomer.

This method may help to explain the dualistic behavior presented by the semicrystalline ionomer when passing by the low temperature endothermic peak. Samples annealed at low temperatures show evident reordering and, on the contrary, samples annealed at higher temperatures show decrease in their morphological order.

\subsection{Morphological changes in E/MAA-Na ionomer after hydrothermal treatment}

To get the best treatment condition, i.e. achieving high water absorption without melting the PE crystals the wet isothermal annealing (HTT) was done during $3 \mathrm{hs}$ at $60^{\circ} \mathrm{C}$ and $70^{\circ} \mathrm{C}$. At these temperatures the final water uptakes after annealing were $5.5 \pm 0.3 \% \mathrm{w} / \mathrm{w}$ and $9 \pm 0.4 \% \mathrm{w} / \mathrm{w}$, respectively. With these contents, a 'water pool' is created inside the water-swollen ionic cluster. ${ }^{15,16,22}$ The effects of the wet annealing in the E/MAA- $\mathrm{Na}^{+}$ionomer was quantified using all characterization techniques already employed in this work.

To start the effects of the HTT in the optical behavior of the water swollen ionomer was quantified by the q-PLOM and the results are shown in Figure 9. The cross-polarized transmitted light intensity measured at room temperature of the HTT samples, are greater than zero, indicating an increase in the intrinsic birefringence produced by the increasing structural order in the PE crystals, consequence of the structural reorganization caused by the annealing during HTT. On heating, the cross-polarized transmitted light intensity increases still further, effect that is not shown by dry-annealed samples (TT samples), replotted for comparison.

The thermo-optical behavior shows some important aspects and differences between the two HTT samples during the heating cycle. The sample HTT@60 ${ }^{\circ} \mathrm{C}$ shows an increase of the intrinsic birefringence starting at $45^{\circ} \mathrm{C}$. A second slight increase is observed when the sample crosses the $68^{\circ} \mathrm{C}-72^{\circ} \mathrm{C}$ temperature range, indicating that the

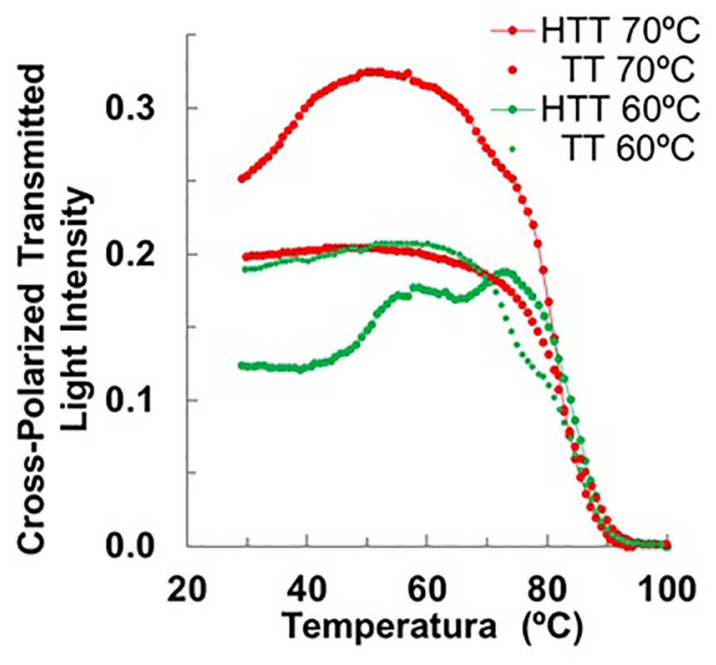

Figure 9. Cross-polarized transmitted light intensity scans obtained by q-PLOM of hydrothermally treated E/MAA-Na+ ionomer after $3 \mathrm{hs}$ at $60^{\circ} \mathrm{C}$ and $70^{\circ} \mathrm{C}$, compared to dry annealed at the same temperatures.

reordering and thickening of the $\mathrm{PE}$ crystals is still present. For the HTT@ $70^{\circ} \mathrm{C}$ sample, the cross-polarized transmitted light intensity starts at greater value, still increases up to approximately $50^{\circ} \mathrm{C}$, and then drops gently with the increasing temperature. In the way it still shows a slight shoulder at $\sim 74^{\circ} \mathrm{C}$ and then, as all samples do, drops to zero.

Again, the DSC analysis helps to explain the thermo-optical behavior shown by q-PLOM. Figure 10 shows the effect of the HTT@60 ${ }^{\circ} \mathrm{C}$ and $@ 70^{\circ} \mathrm{C}$ in the E/MAA-Na ${ }^{+}$ionomer. For comparison results from samples dry-annealed at $60^{\circ} \mathrm{C}$ and $70^{\circ} \mathrm{C}$, previously shown in Figure 4, are replotted. During the heating, both (low and high) characteristics endotherm peaks are presented by each sample. In both wet-treatment temperatures the first endotherm peak was shifted upwards almost $8^{\circ} \mathrm{C}$ from the annealing temperature, when compared to the $12^{\circ} \mathrm{C}$ shift of dry-treated samples. This may indicates that the wet-treated crystals are smaller than the dry-treated crystals at the same treatment temperature. The enthalpy of the high temperature endothermic peak is higher after HTT due to the additional heat flux required for the evaporation of the absorbed water. ${ }^{15}$

During heating, a visible displacement of the baseline is revealed, indicating a change in the specific heat, disclosing a thermal transition. We associated it with a relaxation in the PE chain segments connected to the ionic clusters. For both $\mathrm{HTT}$, at $60^{\circ} \mathrm{C}$ and $70^{\circ} \mathrm{C}$, the relaxation occurs at $45^{\circ} \mathrm{C}$. Above this same limiting temperature q-PLOM curves shows an increase in the cross-polarized transmitted light intensity. An explanation can be sought in the works of Kutsumizu et al. ${ }^{20-22,30}$ whom revealed that the water uptake in the ionic clusters increases the number of PE chain segments in the "intermediate layer" of the swollen cluster. Thus, some PE 


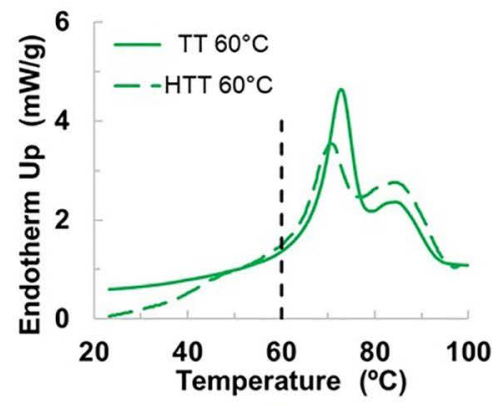

a)

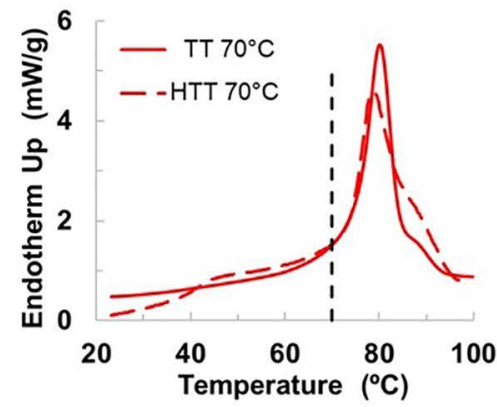

b)

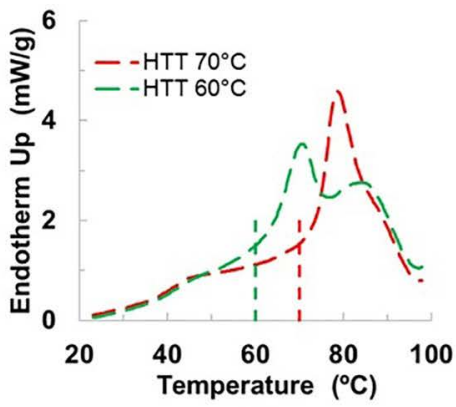

c)

Figure 10. DSC heat scans after dry (continuous line) and wet (broken line) thermal annealing of E/MAA-Na+ ionomer at a) $60^{\circ} \mathrm{C}$, and b) $70^{\circ} \mathrm{C}$. The vertical broken lines set the annealing temperature. Graph c) presents the superposition of the two HTT samples showing the relaxation temperature of the ionic clusters in the $45^{\circ} \mathrm{C}$ range.

chain segment positioned in this intermediate layer, induced by the presence of the water, can undergo a solid-state crystallization immediately after passing by the relaxation temperature, which once restricted their molecular mobility.

On the other hand, the enthalpy of the low endothermic temperature peak of the samples wet annealed is smaller compared with that under dry annealing; thereby it can be thought that the crystalline fraction after the HTT is smaller. A possible reason could be associated with the studies of Kutsumizu, ${ }^{22}$ concluding that the size of the swollen-clusters increases due to the take-up of PE chain segments from their surrounding region. Thus, the amount of PE chain segments available for recrystallization and/or thickening of the crystals during HTT decrease. Otherwise, the decrease in the endothermic heat flux may also be associated with the lower ionic restrictions in the ionic cluster after the HTT. According to the thermal dynamic-mechanical behavior there is a reduction in cohesive strength of the "rigid pathway" demonstrated by the drop in almost $50 \%$ of the initial value of the storage modulus (E') shown in Figure 11.a when compared with the dry samples.

The relaxation of the PE chain segments connected to the swollen ionic clusters was also displayed on the thermal dynamic-mechanical behavior, represented by peaks in Tan $\delta$, as seen in Figure 11.b. The broad relaxation spectrum is due to the non-homogenous structural composition of the clusters, ${ }^{23}$ besides the destabilizing effect produced by the presence of water. The temperatures of the Tan $\delta$ peak are shifted upwards several degrees, compared to those recorded in DSC and q-POLM due to the difference in DMTA heating rate. Thus, when the semi crystalline ionomer is hydrothermally treated, the morphological structures formed will have higher thermal instability, because water acts as a plasticizer within the clusters. That is the reason why the increase in cross-polarized transmitted light intensity (i.e. intrinsic birefringence) starts at lower temperature in the sample with HTT@70 $70^{\circ}$, the PE segments being easily released out of the clusters.

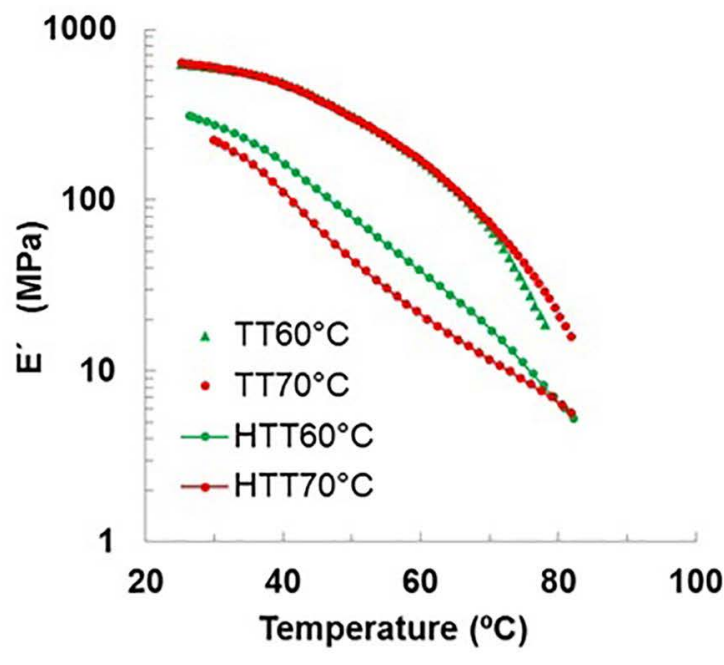

a)

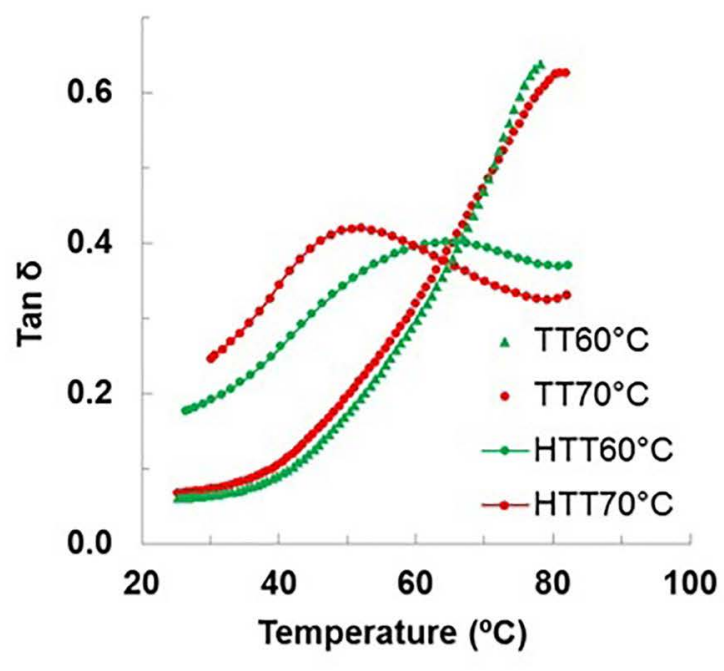

b)

Figure 11. a) Storage modulus ( $\left.E^{\prime}\right)$ and b) Damping (Tan $\delta$ ) as a function of temperature of E/MAA-Na+ ionomer after dry and wet heat treatment @ $60^{\circ} \mathrm{C}$ and $70^{\circ} \mathrm{C}$. 
Still in Figure 9, the HTT@60 $6{ }^{\circ} \mathrm{C}$ sample have an increase in the cross-polarized transmitted light intensity when passing by the temperature range of $68^{\circ} \sim 72^{\circ} \mathrm{C}$, which was associated with a new reorganization of PE crystals. Figure 12 shows the diffraction patterns of the samples after HTT @ $60^{\circ} \mathrm{C}$ and $70^{\circ} \mathrm{C}$, where the diffraction peaks of the PE crystals at $21^{\circ}$ and $23^{\circ}$ are clearly visible. The diffraction peak intensity is higher in samples that were hydrothermally treated (HTT), the resulting crystals have a higher structural order compared to the dry-annealed ones. The plasticizing effect of the water into ionic clusters allowed that the wet-annealing formed better ordered crystals, due to the increased molecular mobility, which better exclude non-crystallizable MAA mers.

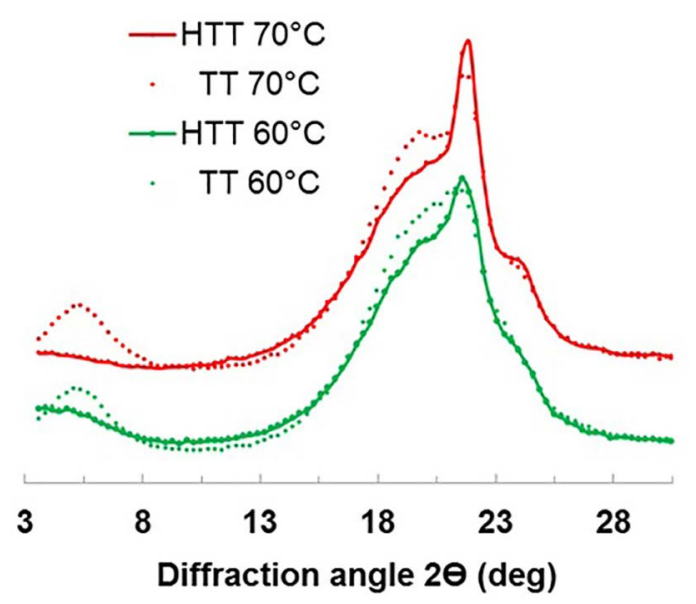

Figure 12. X-Ray diffraction patterns of hydrothermally treated $\mathrm{E} / \mathrm{MAA}-\mathrm{Na}+$ ionomer at $60^{\circ} \mathrm{C}$ and $70^{\circ} \mathrm{C}$ during $30 \mathrm{~min}$.

The reduction of the electrostatic forces also allowed the visualization of solid-state reordering in the q-PLOM for HTT@60 $\mathrm{C}$ sample, when crossing the low temperature endothermic peak range, corroborating the solid-state molecular reordering proposed here. When the semi-crystalline ionomer is dry-annealed and submitted to reheating, the electrostatic forces from the ionic cluster reduces the mobility of PE chain segments, avoiding the detection of the reordering when passing by the temperature range of the low endothermic peak.

Finally the characteristic ionic peak at $3.9^{\circ}$ shifts to smaller diffraction angles due to the growth of the ion clusters and eventually vanishes from the measured diffraction angle range, confirming the increase in the ionic clusters size done by the hydrothermal heat treatment.

\subsection{Morphological solid-state evolution of E/ MAA-Na+ ionomer under dry and wet conditions}

From the thermal and thermo-optical behavior presented in this paper and taking into account the concepts developed by the research groups of Register et al. and Kutsumizu et al., the morphology of the semicrystalline ionomer E/MAA$\mathrm{Na}+$ and its evolution during dry and wet annealings can be schematized in Figure 13. The morphology is represented before and after undergoing the annealing in dry and wet conditions. In this representation, the crystalline PE lamella is intentionally augmented, in order to better visualize the MAA mers scattered inside the non-ordered PE chain segments. As already mentioned, the degree of crystallinity (from DSC) of sample annealed at room temperature is only $17 \%$. The E/MAA- $\mathrm{Na}^{+}$ionomer dry-annealed at room temperature shows a morphology having segregated highly imperfect quasi-crystals, which do not interfere with the cross-polarized light nor with the X-ray diffraction, than lacking of short range order, ionic clusters and the continuous surrounding amorphous region.

The PE chains having a random incorporation of MAA and MAA-Na+ groups (open and closed dots, respectively) along the PE chain length, sets in the solid state forming these quasi-crystals, made by PE chain segments arranged with varying content of chain folding. The MAA and MAA-

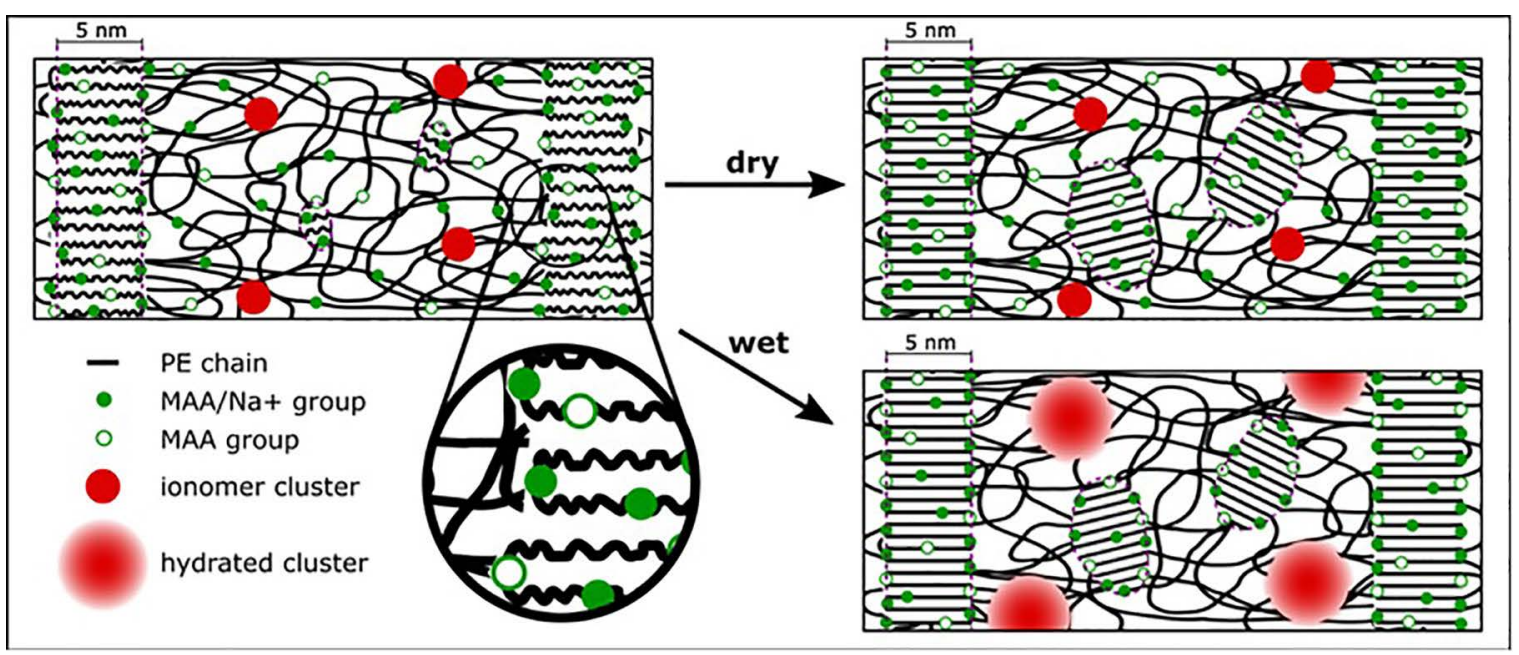

Figure 13. Schematic morphological solid-state evolution of E/MAA-Na ${ }^{+}$ionomers under $30 \mathrm{~min}$ thermal annealing in dry and wet conditions. 
$\mathrm{Na}+$ groups are present in a ratio of $3: 1$, corresponding to the degree of neutralization of the ionomer used.

Upon heating, these quasi-crystals remain intact up to the relaxation of the PE chain segments connected to the ionic clusters. Above that the PE chain segments get sufficient mobility to rearrange themselves into better organized structures. Depending the original level of chain folding the formed crystals tend to be small fringed micellar structures, absorbing energy for doing this transformation, forming one of the PE crystals population. On the other hand quasi-crystals with much higher folded chains content tend to rearrange into imperfect lamellar structures with varying thickness, forming the second PE crystals population.

When performing the dry annealing, at temperatures between the first and second endothermic peaks shown by the DSC, reordering occurs in the packing of the PE chain segments in the initial quasi-crystals. The chain packing level continuously increases by partial exclusion of noncrystallizable MAA mers from the imperfect crystals. The average PE lamella thickness of the crystals upon annealing approaches the average distance between MAA groups, i.e. $\sim 5 \mathrm{~nm}$ ( $\sim 20$ ethylene mers). The same happens to the initial small fringed micellar structures of the PE crystals which thicken up to the same length. At temperatures above $76^{\circ} \mathrm{C}$ all PE crystals melt, with a difference of $\sim 7^{\circ} \mathrm{C}$ between the two populations.

The wet-annealing swollen and plasticizes the ionic clusters as the result of water molecules uptake. It increases the number of PE segments inside them by the incorporation of ethylene chain segments having MAA and MAA/Na+ mers coming from surrounding amorphous regions and disassembling small micellar crystals. Their reordering is facilitated by the reduction of the ionic forces between aggregates, undergoing solid-state crystallization above their relaxation temperature.

\section{Conclusions}

The standard DSC heating thermogram of a semicrystalline sodium neutralized poly(ethylene-random-methacrylic acid) $(\mathrm{E} / \mathrm{MAA}-\mathrm{Na}+)$ ionomer set from the melt, after relaxing at room temperature during two weeks, shows two typical endothermic broad peaks: one in the temperature range of $50-70^{\circ} \mathrm{C}$, known in the literature as the "low temperature endothermic peak", and another in the range of $80^{\circ} \mathrm{C}$, also recognized as the melting of the primary polyethylene crystals. Deconvolution of these two peaks using symmetrical theoretical curves has revealed that in fact each one of them is composed by two peaks. Their maximum peak temperatures and enthalpy were analyzed.

These thermal responses are also shown by thermo-optical measurement. The ionomer shows no birefringence at room temperature, which is maintained up to approximately $50^{\circ} \mathrm{C}$. Above that birefringence (as cross-polarized transmitted light intensity) appears, growing fast up showing two peaks, one centered at $55^{\circ} \mathrm{C}$ and another at $80^{\circ} \mathrm{C}$. Heating up further the birefringence drops down quickly to zero.

The "low temperature endothermic peak" is interpreted as the starts of a structural endothermic reordering of the PE chain segments in the initial quasi-crystals. These structures are amorphous regions formed by PE chain segments, with incorporated MAA non-crystallizable mers. The reordering happens in two population of highly imperfect polyethylene crystals set from the melt, differing in the length of the PE chain segments (set by the average number of methylenes between two consecutive MAA mers), and in the folded chain content. The structural reordering only starts above the relaxation temperature of the PE chain segments connected to the ionic clusters, a high electrostatic barrier energy set by the ionic aggregates. The energy stored in the crystals during the endothermic reordering phenomenon is accumulated and used to melt them down when their melting temperature is reached.

The use of a wet-annealing treatment not only shifts the reordering (low temperature) endothermic peak to higher temperatures but also shows a change in the DSC baseline in the $50^{\circ} \mathrm{C}$ range, revealing the relaxation effect of the plasticized ionic clusters. When the applied mechanical deformation is dynamic, as in DMTA analysis, this relaxation appears as a damping $(\tan \delta)$ peak, which shifts to lower temperatures with higher hydrothermal annealing temperatures and so water take up.

\section{Acknowledgment}

This study was financed in part by the Coordenação de Aperfeiçoamento de Pessoal de Nível Superior - Brasil (CAPES) - Finance Code 001". - ProEx to PPG-CEM, in part by Conselho Nacional de Desenvolvimento Científico e Tecnológico (CNPq) for granting scholarship to $\mathrm{S}$. V. Canevarolo (PQ 311790/2013-5) and the Programa de Pós-Graduação em Ciência e Engenharia de Materiais (PPGCEM) of UFSCar for providing the laboratorial facilities.

\section{References}

1. Eisenberg A, Rinaudo M. Polyelectrolytes and ionomers. Polymer Bulletin. 1990;24(6):671.

2. Tant MR, Mauritz KA, Wilkes GL. Ionomers - Synthesis, structure, properties and applications. Dordrecht: Springer Netherlands; 1997. DOI: 10.1007/978-94-009-1461-2

3. Antony P, De SK. Ionic thermoplastic elastomers: A review. Journal of Macromolecular Science, Part C Polymer Reviews. 2001;41(1-2):41-77.

4. Scogna RC, Register RA. Yielding in ethylene/methacrylic acid ionomers. Polymer (Guildf). 2009;50(2):585-590.

5. Scogna RC, Register RA. Plastic deformation of ethylene/ methacrylic acid copolymers and ionomers. Journal of Polymer Science Part B Polymer Physics. 2009;47(16):1588-1598. 
6. Hara M, Sauer JA. Mechanical Properties of lonomers. Journal of Macromolecular Science, Part C Polymer Reviews. 1994;34(3):325-363.

7. Kalista SJ Jr., Ward TC, Oyetunji Z. Self-Healing of Poly(Ethylene-co-Methacrylic Acid) Copolymers Following Projectile Puncture. Mechanics of Advanced Materials and Structures. 2007;14(5):391-397.

8. Lu L, Li G. One-Way Multishape-Memory Effect and Tunable Two-Way Shape Memory Effect of Ionomer Poly(ethyleneco-methacrylic acid). ACS Applied Materials \& Interfaces. 2016;8(23):14812-14823.

9. Capek I. Nature and properties of ionomer assemblies. II. Advances in Colloid and Interface Science. 2005;118(1-3):73112.

10. Buitrago CF, Jenkins JE, Opper KL, Aitken BS, Wagener KB, Alam TM, et al. Room Temperature Morphologies of Precise Acid- and Ion-Containing Polyethylenes. Macromolecules. 2013;46(22):9003-9012.

11. Buitrago CF, Alam TM, Opper KL, Aitken BS, Wagener KB, Winey KI. Morphological Trends in Precise Acid- and Ion-Containing Polyethylenes at Elevated Temperature. Macromolecules. 2013;46(22):8995-9002.

12. Marx CL, Cooper SL. The crystallinity of ionomers. Journal of Macromolecular Science, Part B Physics. 1974;9(1):19-33.

13. Eisenberg A, Hird B, Moore RB. A new multiplet-cluster model for the morphology of random ionomers. Macromolecules. 1990;23(18):4098-4107.

14. Tadano K, Hirasawa E, Yamamoto H, Yano S. Order-disorder transition of ionic clusters in ionomers. Macromolecules. 1989;22(1):226-233.

15. Kutsumizu S, Nagao N, Tadano K, Tachino H, Hirasawa E, Yano S. Effects of water sorption on the structure and properties of ethylene ionomers. Macromolecules. 1992;25(25):6829-6835.

16. Yano S, Tadano K, Nagao N, Kutsumizu S, Tachino H, Hirasawa E. Dielectric relaxation studies on water absorption of ethylene ionomers. Macromolecules. 1992;25(26):7168-7171.

17. Tachino H, Hara H, Hirasawa E, Kutsumizu S, Tadano K, Yano $\mathrm{S}$. Dynamic mechanical relaxations of ethylene ionomers. Macromolecules. 1993;26(4):752-757.

18. Kutsumizu S, Schlick S. Self-Assembling of Ethylene-Methacrylic Acid Ionomers in Aqueous Solutions and as Swollen Membranes from ESR Spectra of Amphiphilic Spin Probes. 2. Dynamics in Aggregates and Correlation with Thermal Transitions. Macromolecules. 1997;30(8):2329-2336.

19. Kutsumizu S, Tadano K, Matsuda Y, Goto M, Tachino H, Hara H, et al. Investigation of Microphase Separation and Thermal Properties of Noncrystalline Ethylene Ionomers. 2. IR, DSC, and Dielectric Characterization. Macromolecules. 2000;33(24):9044-9053.

20. Kutsumizu S, Goto M, Yano S, Schlick S. Structure and Dynamics of Ionic Aggregates in Ethylene Ionomers and Their Effect on Polymer Dynamics: A Study by Small-Angle X-ray Scattering and Electron Spin Resonance Spectroscopy. Macromolecules. 2002;35(16):6298-6305.
21. Kutsumizu S, Goto M, Yano S. Electron Spin Resonance Studies on Sodium-Neutralized Ethylene Ionomers: MicrophaseSeparated Structure and Thermal Behaviors. Macromolecules. 2004;36(13):4821-4829.

22. Kutsumizu S, Schlick S. Structure and dynamics of ionic aggregates in ethylene ionomer membranes: recent electron spin resonance (ESR) studies. Journal of Molecular Structure. 2005;739(1-3):191-198.

23. Miwa Y, Kondo T, Kutsumizu S. Subnanoscopic Mapping of Glass Transition Temperature around Ionic Multiplets in Sodium-Neutralized Poly(ethylene- random -methacrylic acid) Ionomer. Macromolecules. 2013;46(13):5232-5236.

24. Quiram DJ, Register RA, Ryan AJ. Crystallization and Ionic Associations in Semicrystalline Ionomers. Macromolecules. 1998;31(4):1432-1435.

25. Wakabayashi K, Register RA. Micromechanical interpretation of the modulus of ethylene-(meth)acrylic acid copolymers. Polymer (Guildf). 2005;46(20):8838-8845.

26. Wakabayashi K, Register RA. Morphological Origin of the Multistep Relaxation Behavior in Semicrystalline Ethylene/ Methacrylic Acid Ionomers. Macromolecules. 2006;39(3):10791086.

27. Grady BP, Floyd JA, Genetti WB, Vanhoorne P, Register RA. $\mathrm{X}$-ray absorption spectroscopy studies of zinc-neutralized ethylene-methacrylic acid ionomers. Polymer (Guildf). 1999;40(2):283-288.

28. Loo YL, Wakabayashi K, Huang YE, Register RA, Hsiao BS. Thin crystal melting produces the low-temperature endotherm in ethylene/methacrylic acid ionomers. Polymer (Guildf). 2005;46(14):5118-5124.

29. Longworth R, Vaughan DJ. Physical structure of ionomers. Nature. 1968;218:85-87.

30. Kutsumizu S, Hara H, Schlick S. Self-Assembling of Ethylene Methacrylic Acid Ionomers in Aqueous Solutions and as Swollen Membranes, from ESR Spectra of Amphiphilic Spin Probes. 1. Structure of Aggregates and Effect of Ionomer Concentration. Macromolecules. 1997;30(8):2320-2328.

31. Tachino H, Hara H, Hirasawa E, Kutsumizu S, Yano S. Water absorption effects on the thermal transition and stiffness of ethylene ionomers. Journal of Applied Polymer Science. 1995;55(1):131-138.

32. Reynolds PJ. A Surlyn ${ }^{\circledR}$ Ionomer as a Self-Healing and SelfSensing Composite. [Thesis]. Birminghan: School of Metallurgy and Materials, College of Engineering \& Physical Sciences; 2012. Available from: http://etheses.bham.ac.uk/3272/

33. Du Pont. DuPont ${ }^{\mathrm{TM}}$ Surlyn ${ }^{\circledR}$ PC-2000 datasheet. Geneva: DuPont; 2012.

34. Rui Y, Grady BP. Long-time crystallization kinetics in zincneutralized ethylene-methacrylic acid ionomers. Thermochimica Acta. 2013;565:183-193.

35. Goddard RJ, Grady BP, Cooper SL. The Room Temperature Annealing Peak in Ionomers: Ionic Crystallites or Water Absorption? Macromolecules. 1994;27(7):1710-1719. 
36. Ray AK. Effects of chemical constituents on crystalline properties of ethylene ionomers. Journal of Thermal Analysis. 1996;46(6):1527-1539.

37. Kohzaki M, Tsujita Y, Takizawa A, Kinoshita T. The crystallization and formation of cluster of ethylene ionomer during physical aging. Journal of Applied Polymer Science. 1987;33(7):23932402 .

38. Lu L, Alamo RG, Mandelkern L. Lamellar Thickness Distribution in Linear Polyethylene and Ethylene Copolymers. Macromolecules. 1994;27(22):6571-6576.

39. Keating MY, McCord EF. Evaluation of the comonomer distribution in ethylene copolymers using DSC fractionation. Thermochimica Acta. 1994;243(2):129-145.

40. Sanchez IC, Eby RK. Thermodynamics and Crystallization of Random Copolymers. Macromolecules. 1975;8(5):638-641.

41. Bicalho LA, da Silva JMJ, Covas JA, Canevarolo SV. Real-time thermo-optical analysis of polymer samples by quantitative polarized optical microscopy. Journal of Thermal Analysis and Calorimetry. 2017;130(3):2093-2103. DOI: 10.1007/ s10973-017-6714-5

42. Berl JH, Santos AMC, Lucas AA, Canevarolo SV. Quantitative characterization of polymer crystallization via instrumented polarized light optical microscopy. In: Europe Africa 2014
Regional Conference of the International Polymer Processing Society; 2014 Oct 19-23; Tel Aviv, Israel.

43. Matsui K, Seno S, Nozue Y, Shinohara Y, Amemiya Y, Berda $\mathrm{EB}$, et al. Influence of Branch Incorporation into the Lamella Crystal on the Crystallization Behavior of Polyethylene with Precisely Spaced Branches. Macromolecules. 2013;46(11):44384446.

44. Tsujita Y, Shibayama K, Takizawa A, Kinoshita T, Uematsu I. Thermal properties of ethylene ionomers. Journal of Applied Polymer Science. 1987;33(4):1307-1314.

45. Höhne GWH. Another approach to the Gibbs-Thomson equation and the melting point of polymers and oligomers. Polymer (Guildf). 2002;43(17):4689-4698.

46. Subramaniam CP. Morphology, Crystallization and Melting Behaviors of Random Copolymers of Ethylene with 1-Butene, 1-Pentene and 1-Hexene. [Dissertation]. Blaksburg: Virginia Polytechnic Institute and State University; 1999. Available from: http://hdl.handle.net/10919/28064

47. Spencer MW, Wetzel MD, Troeltzsch C, Paul DR. Effects of acid neutralization on the properties of $\mathrm{K}^{+}$and $\mathrm{Na}^{+}$poly(ethylene-comethacrylic acid) ionomers. Polymer (Guildf). 2012;53(2):569580 . 